\title{
Concomitant Use of Sea Cucumber Organic Extract and Radiotherapy on Proliferation and Apoptosis of Cervical (HeLa) Cell Line
}

\author{
Javad Baharara, ${ }^{1,}$ Elaheh Amini, ${ }^{2}$ and Vahid Vazifedan ${ }^{3}$ \\ ${ }^{1}$ Department of Biology, Research Center for Animal Development Applied Biology, Mashhad Branch, Islamic Azad University, Mashhad, IR Iran \\ ${ }^{2}$ Animal Developmental Biology, Young Researchers and Elicit Club, Mashhad Branch, Islamic Azad University, Mashhad, IR Iran \\ ${ }^{3}$ Mashhad Branch, Islamic Azad University, Mashhad, IR Iran \\ "Corresponding author: Javad Baharara, Department of Biology, Research Center for Animal Development Applied Biology, Mashhad Branch, Islamic Azad University, Mashhad, \\ IR Iran. E-mail: baharara@yahoo.com
}

Received 2015 January 12; Accepted 2015 November 16.

\begin{abstract}
Background: Cervical carcinoma is gynecologic malignancy with conventional treatment modality but drug resistance interferes with current therapeutic methods. Therefore, identification of novel new modality with low toxicity has uniquely favorable strategy. Objectives: The aim of this study is evaluation of concomitant use of sea cucumber organic extract and radiotherapy on ovarian cancer.

Materials and Methods: In this in vitro experimental study, HeLa cancer cells were cultured and suspended in RPMI (Roswell Park Memorial Institute) 1640 medium supplemented with 10 \% FBS (Fetal Bovine Serum), $1 \%$ antibiotic. Cells were treated with extract at different concentrations ( 0 to $100 \mu \mathrm{g} / \mathrm{mL}$ ) for 24 hours. After determination of suitable concentration, the cells were exposed to 2 Gray gamma radiation in presence of extract for 192 seconds and 66 hours were kept in incubator till anti-proliferative assay were evaluated. To assess apoptosis, flow cytometry with PI (Propodium Iodide) and acridine orange staining were performed.

Results: Morphological analysis and results from cytotoxicity assay exhibited that $50 \mu \mathrm{g} / \mathrm{mL}$ of sea cucumber extract alone is considered $\mathrm{IC}_{50}$ and combination of gamma radiation became more valuable in growth inhibition. Also, flow cytometry histogram of treated cells indicated sub-G1 peak demonstrating disturbance in membrane integrity and apoptosis cell death. Fluorescence images have been confirmed apoptosis cell death in treatment groups.

Conclusions: These data indicate that sea cucumber extract as novel resource of aquatic natural products significantly can inhibit cervical cancer cell growth and synergistic effect of natural extract along with radiation therapy was more effective in anti-cervical cancer therapy.
\end{abstract}

Keywords: Aquatic, Pharmaceutical, Radiotherapy, Cervical Neoplasms, Apoptosis

\section{Background}

Cervical carcinoma is one of major health disorder and leading cause of women cancer death with highest morbidity rate in worldwide [1]. There are several therapeutic modalities to fight cervical cancer but the current option is surgery followed by chemotherapy [2]. However one of the most complications to select method of treatment is poor prognosis and relapse of cancer, so as, majority of cervical cancer diagnosed in late stage of disease [3]. The scientific proof established most of patients respond to chemotherapy and cellular reductive surgery, more over radiosensitive features of cervical cancer appropriated radiation therapy as adjuvant against cervical cancer when salvage therapy lead to failure of first and second line chemotherapy [4]. Because combinational therapy has been provided prolonged progression free intervals and due to safe and effective properties of palliative radiotherapy, chemo radiotherapy can consider as another standard approach for treatment of relapses cervical cancer [5].

Cisplatin and carboplatin based chemotherapy is popular drug regimen to enhance survival of cervical cancer patients, therefore, recognition of novel complementary treatments leads to achieve treatment process advancement [6]. A promising alternative to improve therapeutic efficacy of cervical malignancy is application of anti tumor natural products with advantages of low toxicity, recruitment of apoptosis and attenuation of modern therapies side effects [7]. Natural substances are appreciable substitution of synthetic chemicals with minimum toxicity that this property is crucial for human health care [8]. Apoptosis is a desirable cell death induced in cancer research to regulate cell cycle disturbance and control cell proliferation that characterized by morphological alterations including DNA fragmentation and membrane integrity [6]. Marine organisms offer valuable source of secondary metabolites which play essential role in preven- 
tion of human disorders and present pharmacological potency applied in drug discovery [9]. Marine invertebrate particularly sea cucumbers belonging to echinoderm have provided impressive useful bioactive compounds such as vitamins, carbohydrates, saponin, sterols and ions with unique biomedical effects such as anti microbial, anti inflammatory, antioxidant, anti fungal and anti cancer activities and possess commercial value and consume as functional food and nutraceutical in traditional medicine [10].

The anti-cancer activities of sea cucumber whole extract already have been studied [11]. It has also eligibility significant cytotoxic effect on human non-small lung carcinoma, leukemia and human colon adenocarcinoma cells. Nevertheless, there are no reports related with radiosensitive activity of sea cucumber extract.

\section{Objectives}

In addition the effect of sea cucumber whole extract and its radio sensitivity on HeLa cervical cancer has not been investigated yet. Therefore, the aim of this experiment was evaluation the anti-proliferative and apoptogenic effect of Persian Gulf sea cucumber extract enriched with glycosaminoglycans and steroids simultaneously with gamma radiation therapy as combinational therapy in a cervical cancer cells in vitro.

\section{Materials and Methods}

\subsection{Chemicals}

In this in vitro experimental study, HeLa human cervical cancer cells were purchased from NCBI (National Cell Bank of Iran). RPMI (Roswell Park Memorial Institute) 1640 Medium, FBS (Fetal Bovine Serum), trypsinEDTA, and antibiotic (Penicillin-streptomycin) were obtained from Gibco-USA. MTT (3-[4, 5-dimethyl thiazol-2-yl]2, 5-diphenyl tetrazolium bromide) was prepared from Applichem (USA). PI (propodium iodide) and acridine orange obtained from Sigma (USA). Specimens of the sea cucumber (Sc, Holothuria leucospilota) were obtained from Persian Gulf waters. Methanol, were purchased from Merck (Germany). All ethic aspects were considered.

\subsection{Preparation of Sea Cucumber Whole Extract}

The collected specimens of Holothuria leucospilota obtained from Qeshm Island washed and stored at $-80^{\circ} \mathrm{C}$. For extract construction, sea cucumber samples (about $20 \mathrm{~g}$ ) dried, girded and soaked with $200 \mathrm{~mL}$ methanol. Then, the extract stirred for 3 day at room temperature, filtered through an $11 \mu \mathrm{m}$ Whatman filter, concentrated under vacuum evaporator and stored in $-20^{\circ} \mathrm{C}$ as sea cucumber extract.

\subsection{Cell Culture}

HeLa (Human epithelial cervical carcinoma) was purchased from Pasture institute of Tehran, Iran and were grown in RPMI medium supplemented with 10\% FBS and 1\% penicillin-streptomycin in humidified incubator containing $5 \% \mathrm{CO}_{2}$ at $37^{\circ} \mathrm{C}$.

\subsection{Cell Cytotoxicity Assay (MTT Assay)}

Anti proliferative effect of the sea cucumber extract and gamma radiation against the cervical cancer cell line (HeLa) was investigated by 3-(4, 5-dimethylthiazol-2-yl) -2, 5-diphenyltetrazolium bromide (MTT) assay. For designation of this in vitro experiment, we cultured cells in 2 plates overnight, then the cells of 2 plates, were exposed with different concentrations of the sea cucumber extract $(0$ to 100 $\mu \mathrm{g} / \mathrm{mL}$ ) for 24 hours. After desired time, one plate irradiated by 2 gray (Gy) of $\gamma$-rays. Then both of plates (irradiated and non-irradiated) incubated for 66 hours in $\mathrm{Co}_{2}$ incubator. Then MTT solution $(5 \mathrm{mg} / \mathrm{mL}$ in PBS or Phosphate Buffer Saline) was added to each well for $4 \mathrm{~h}$. Finally MTT solution was discarded and100 $\mu$ L of DMSO (DiMethyl Sulfoxide) was added to each well to resulting formazan was solubilized with DMSO $(100 \mu \mathrm{L})$ and absorbance was measured at $560 \mathrm{~nm}$ in spectrophotometer (Epoch, USA).

\subsection{Apoptotic Detection by Acridine Orange/Propodium Iodide (AO/PI) Staining}

The cultured cells in 6 wells plate treated with defined concentration of sea cucumber methanol extract and gamma irradiation for desired times, then harvested and stained with $10 \mu \mathrm{L}(100 \mu \mathrm{g} / \mathrm{mL}$ acridine orange and 100 $\mu \mathrm{g} / \mathrm{mL}$ propodium iodide mixture) to analysis by fluorescence microscopy.

\subsection{Flow Cytometry Analysis by Propodium Iodide}

To determine the apoptotic effect of sea cucumber methanol extract and gamma irradiation, flow cytometry analysis were examined by propodium iodide to investigate DNA fragmentation. Briefly, after treatment, the cells were washed with PBS and resuspended with propodium iodide (PI; Sigma) containing 0.1\% sodium citrate plus 0.1\% Triton $\mathrm{X} 100$ at $37^{\circ} \mathrm{C}$ for $30 \mathrm{~min}$ and then placed at $4^{\circ} \mathrm{C}$ in the dark for 10 minutes and the sub-G1 peak was evaluated using a FACScan laser flow cytometer (FACSCalibur, Becton Dickinson, USA).

\subsection{Statistical Analysis}

All results were repeated at least triplicate and expressed as mean \pm SEM. The statistical significance was evaluated by SPSS-16 software, independent t-test analysis. For all comparisons, the level of $\mathrm{P} \leq 0.05$ was considered significant. 


\section{Results}

4.1. Effect of Combination Therapy of Radiation Therapy and Sea Cucumber Methanol Extract on Cell Proliferation of HeLa Cells

HeLa cells were exposed with different concentrations of sea cucumber extract $(0-100 \mu \mathrm{g} / \mathrm{mL})$ for 24 hours. Then irradiation $2 \mathrm{~Gy} \gamma$-rays was performed and then incubated for 66 hours. The results indicated sea cucumber extract could attenuate cell growth in cervical carcinoma cells as a dose dependent manner and sensitize HeLa cells to radiation-induced cytotoxicity (Figure 1 ).

Figure 1. The Anti Proliferative Activity of Sea Cucumber Extract (sc) and Gamma Radiotherapy (rad) on Cell Growth of HeLa Cell Line

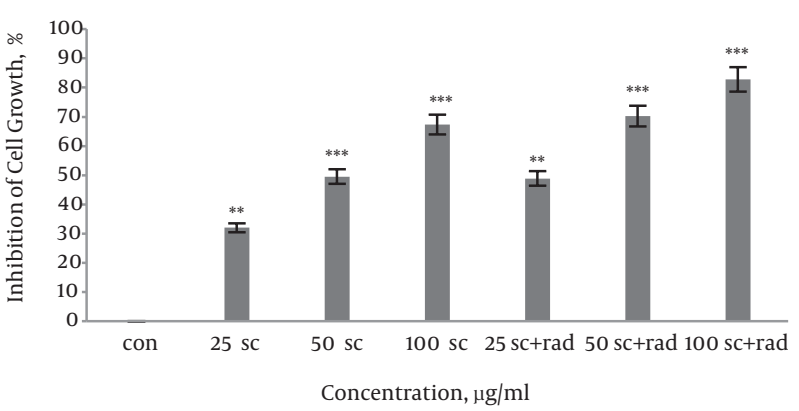

The cells incubated with different concentration of sea cucumber extract for 24 hours, then were exposed to 2 Gy $\gamma$-rays. ${ }^{*} \mathrm{P}<0.05,{ }^{* *} \mathrm{P}<0.01,{ }^{* * *} \mathrm{P}<0.001$, mean \pm SEM.

Simultaneously effect of gamma radiation and sea cucumber methanol extract induced apoptosis cervical cell death: The apoptosis cell death was measured with flow cytometry histogram of PI and acridine orange staining. Sea cucumber extract ( $0-100 \mu \mathrm{g} / \mathrm{mL})$ increased a sub-G1 peak in treated cells (B: 50 sc, C: 100 sc, D: 25sc + rad, E: 50 sc + rad) compared with untreated cells (A) suggesting loss of membrane integrity involved in its toxicity (Figure 2).

Advent of orange color revealed apoptosis in the response of treatment with sea cucumber extract and gamma radiation. Results exhibited that sea cucumber extract induced cervical cancer cell radiation sensitivity and apoptosis in a dose dependent manner (A: control, B: 50 sc, C: 100 sc, D: 25 sc + rad, E: 50 sc + rad) (Figure 3).

\section{Discussion}

In this study, we investigated the cytotoxic effect of sea cucumber $H$. leucospilota and its concomitant effect with gamma radiation against cervical cancer cells. According to the figures 2 and 3; apoptosis induction in HeLa cells were observed after treatment with $\mathrm{IC}_{50}$ concentration of sea cucumber extract (50 $\mu \mathrm{g} / \mathrm{mL}$ ) and with radiotherapy
(25 $\mu \mathrm{g} / \mathrm{mL}+2$ Gy gamma radiations). In PI flow cytometry analysis sub G1 peak in flow cytometrical histogram have been indicated DNA fragmentation and loss of membrane integrity that was established by detection of sub-G1 peak under treatment with 50 and $100 \mu \mathrm{g} / \mathrm{mL}$ sea cucumber extract and 25 and $50 \mu \mathrm{g} / \mathrm{mL}$ sea cucumber extract in combination with radiotherapy. Moreover, our results exhibited that sea cucumber extract concurrently with 2 Gy gamma radiation induced apoptosis that was displayed by appearance of yellow, orange color in AO/PI staining suggesting involvement of apoptotic cell death in combination treatment toxicity so that induction of apoptosis can be profit in treatment of cervical cancer and avoid of recurrence. Since, cervical cancer cells have developed various mechanisms to drug resistance and evasion of apoptosis, therapeutic methods that utilized from natural occurring agents can overwhelm to these complications with modulation of apoptosis [12]. Natural compounds act as chemo preventive leads to suppress tumorogenesis and overcome to cancer resistance against conventional treatment options [13]. Hence, the identification of natural derived compounds has progressively attributed to improve patients survival rate [14]. Several features candidate natural constituent application such as suppression of cell growth, regulation of cell cycle and induction of apoptosis in cancer research [15]. Marine biodiversity is extraordinary source for assessment of numerous anticancer drugs and health beneficial ingredients derived from marine invertebrate provide unique structural diversity for development of pharmaceutical researches [16]. Different bioactive metabolites have recognized from sea cucumbers with anti proliferative potentials [17]. The presence of triterpenoid glycosides, sulfated polysaccharide, and cerebrosides in sea cucumber body wall confer biological potency to sea cucumbers that is responsible for biomedical applications particularly in oncology [10]. Previous investigations proved anti cancer activity of sea cucumber whole extract and its constituents [11]. Ogushi et al. reported the aqueous extract of sea cucumber displayed cytostatic effect on human colon adenocarcinoma Caco-2 cells and revealed anti growth effect as concentration dependent manner [18]. The conducted study by Althunibat et al. demonstrated the antiproliferative and antioxidant effects of sea cucumber species of Holothuria scabra, H. leucospilota and Stichopus chloronotus so that all organic extract of sea cucumber indicated cytotoxic potential against A549 and C33A cancer cells [19]. In other survey, Althunibat et al. were examined the cytotoxic and antioxidant effect of two sea cucumber aqueous and organic extract and showed that that both extracts revealed antioxidant effect but the organic extract of Stichopus horrens indicate highest growth inhibitory activity which candidate them as therapeutic 
A

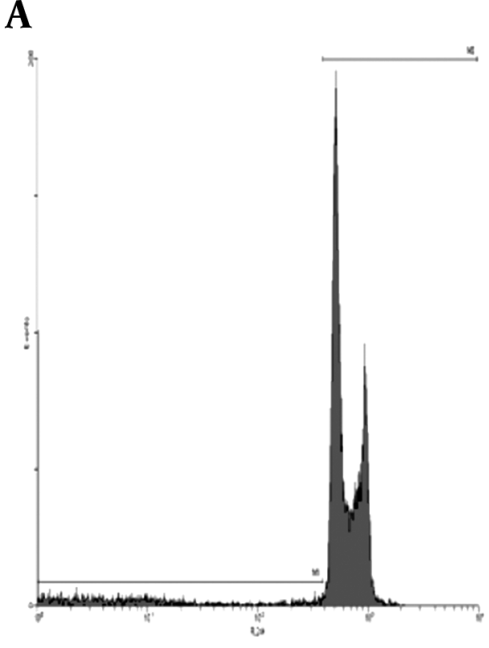

D
B

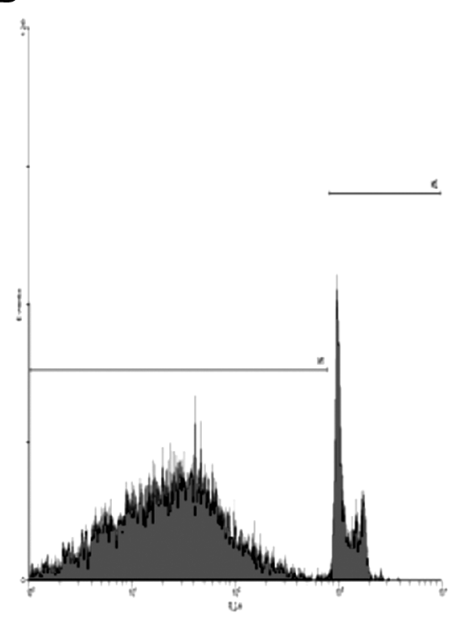

C

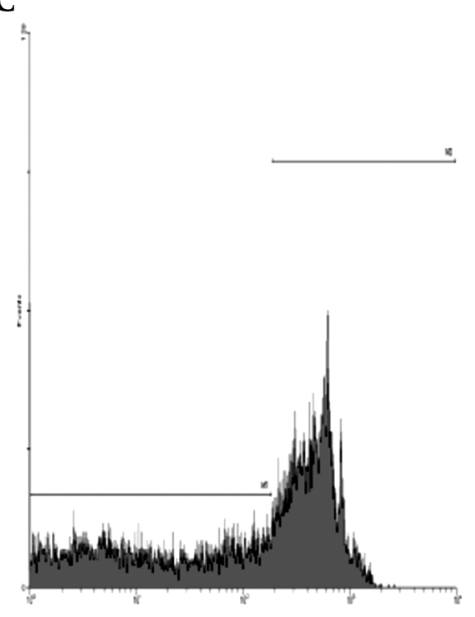

$\mathbf{E}$

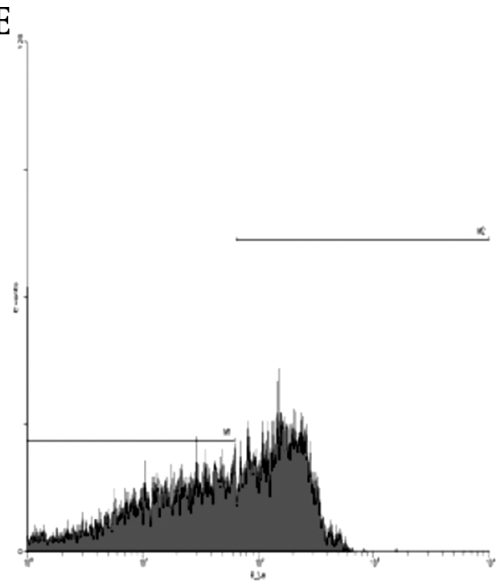

natural resources in cancer researches [20]. Cytotoxic effects of sea cucumber have been also indicated in various cell lines but its growth inhibitory effect on cervical cancer cells have not been investigated.

To assess the anti proliferative effect of sea cucumber whole extract on cervical cancer cells, the cells were exposed to serial concentration of sea cucumber for 24 hours, and cell cytotoxicity was determined by MTT assay. Our findings confirmed that sea cucumber has anti cervical cancer activities and induced apoptosis in a dose dependent manner. Our results emphasized that sea cucumber has cytotoxic and anti-carcinogenic activities against cervical cancer. According to the figures1; cell survival in HeLa cells was reduced after exposure to sea cucumber in a dose dependent manner, so that $50 \mu \mathrm{g} / \mathrm{mL}$ of sea cucum- ber extract and $25 \mu \mathrm{g} / \mathrm{mL}+2$ Gy gamma radiations were considered $\mathrm{IC}_{50}$ value. Co administration of chemotherapeutic agents with radiation therapy has been studied [21]. Kaneyasu et al. studied the concomitant effect of cisplatin with radiotherapy on cervical cancer and indicated that combination therapy of drug and radiation remarkably improved the in vitro radio sensitivity of cervical cancer cells [22]. Schmid et al. examined the effects of radiation with or without chemotherapy on cervical cancer. They reported that the drug increased the response of these cells to radiotherapy and reducing cisplatin exposure enhances distance metastasis [23]. In another study accomplished by Petrelli platinum based chemotherapy plus radiotherapy restores cervical cancer cells sensitivity and effectively postpone recurrence of cervical cancer [21]. 


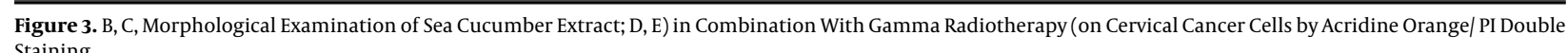
Staining
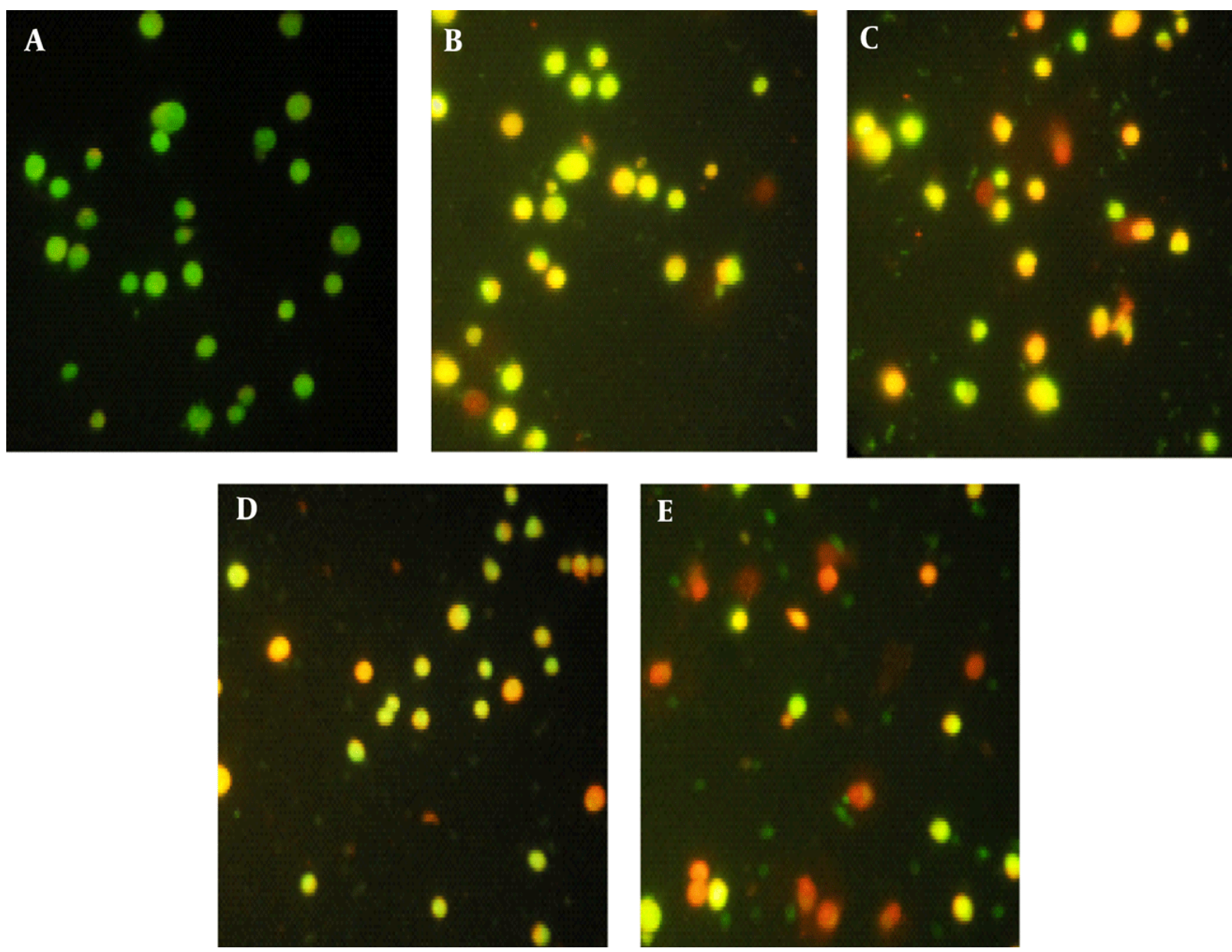

Green color, orange color and red color respectively point to alive cells, apoptotic cells and necrotic cells.

Since no publication is documented on the synergistic effects of sea cucumber with radiotherapy related to cervical cancer treatment, in this study we evaluated the cytotoxic combination treatment of sea cucumber with radiation on HeLa cells and confirmed that simultaneously application of sea cucumber extract and radiation enhanced HeLa apoptosis cell death. In conclusion, this study is the first preliminary study demonstrated the cytotoxic effects of sea cucumber organic extract through apoptosis induction and clearly indicated the synergistic effect of sea cucumber organic extract with radiotherapy administrated more toxicity on HeLa cancer cells through recruitment of apoptosis cell death. Therefore, the combination therapy of sea cucumber extract and radiotherapy can be considered as adjunct in cervical cancer treatment in future. Finally, we suggest further evaluation of apoptosis under- lied mechanisms to increase effectiveness of this combinational treatment.

\section{Acknowledgments}

This work was supported by vice chancellor scientific research of Mashhad branch, Islamic Azad University. The authors have special thanks to the Omid hospital lab of Mashhad.

\section{Footnotes}

Authors' Contribution: Design, materials and supervision: Javad Baharara; data collection: Elaheh Amini; analysis and literature search: Vahid Vazifedan. 
Funding/Support: Islamic Azad University, Mashhad; code research: 1113051791200201/1.

\section{References}

1. Di Domenico F, Foppoli C, Coccia R, Perluigi M. Antioxidants in cervical cancer: chemopreventive and chemotherapeutic effects of polyphenols. Biochim Biophys Acta. 2012;1822(5):737-47. doi: 10.1016/j.bbadis.2011.10.005. [PubMed: 22019724].

2. Neergheen VS, Bahorun T, Taylor EW, Jen LS, Aruoma OI. Targeting specific cell signaling transduction pathways by dietary and medicinal phytochemicals in cancer chemoprevention. Toxicology. 2010;278(2):229-41. doi: 10.1016/j.tox.2009.10.010. [PubMed: 19850100].

3. Bolles O, Borowsky M. Port-site metastasis following robotic-assisted radical hysterectomy for squamous cell cervical cancer. Gynecol Oncol Case Rep. 2011;2(2):32-4. doi: 10.1016/j.gynor.2011.11.003. [PubMed: 24371608].

4. Harima Y, Ikeda K, Utsunomiya K, Shiga T, Komemushi A, Kojima H, et al. Identification of genes associated with progression and metastasis of advanced cervical cancers after radiotherapy by cDNA microarray analysis. Int J Radiat Oncol Biol Phys. 2009;75(4):1232-9. doi: 10.1016/j.ijrobp.2009.07.002. [PubMed:19857786].

5. Vidya Priyadarsini R, Senthil Murugan R, Maitreyi S, Ramalingam K, Karunagaran D, Nagini S. The flavonoid quercetin induces cell cycle arrest and mitochondria-mediated apoptosis in human cervical cancer (HeLa) cells through p53 induction and NF-kappaB inhibition. EurJPharmacol. 2010;649(1-3):84-91. doi:10.1016/j.ejphar.2010.09.020. [PubMed: 20858478].

6. Xiao JX, Huang GQ, Zhu CP, Ren DD, Zhang SH. Morphological study on apoptosis Hela cells induced by soyasaponins. Toxicol In Vitro. 2007;21(5):820-6. doi: 10.1016/j.tiv.2007.01.025. [PubMed: 17367985].

7. Xiao JX, Huang GQ, Zhang SH. Soyasaponins inhibit the proliferation of Hela cells by inducing apoptosis. Exp Toxicol Pathol. 2007;59(1):3542. doi: 10.1016/j.etp.2007.02.004. [PubMed: 17582751].

8. Cragg GM, Newman DJ. Natural products: a continuing source of novel drug leads. Biochim Biophys Acta. 2013;1830(6):3670-95. doi: 10.1016/j.bbagen.2013.02.008. [PubMed: 23428572].

9. Lloret J. Human health benefits supplied by Mediterranean marine biodiversity. Mar Pollut Bull. 2010;60(10):1640-6. doi: 10.1016/j.marpolbul.2010.07.034. [PubMed: 20822779].

10. Bordbar S, Anwar F, Saari N. High-value components and bioactives from sea cucumbers for functional foods-a review. Mar Drugs. 2011;9(10):1761-805. doi: 10.3390/md9101761. [PubMed: 22072996].

11. Wijesinghe WA, Jeon YJ, Ramasamy P, Wahid ME, Vairappan CS. Anticancer activity and mediation of apoptosis in human HL-60 leukaemia cells by edible sea cucumber (Holothuria edulis) extract.
Food Chem. 2013;139(1-4):326-31. doi: 10.1016/j.foodchem.2013.01.058 [PubMed: 23561113].

12. Kim HG, Song H, Yoon DH, Song BW, Park SM, Sung GH, et al. Cordyceps pruinosa extracts induce apoptosis of HeLa cells by a caspase dependent pathway. J Ethnopharmacol. 2010;128(2):342-51. doi: 10.1016/j.jep.2010.01.049. [PubMed: 20138133].

13. Nobili S, Lippi D, Witort E, Donnini M, Bausi L, Mini E, et al. Natural compounds for cancer treatment and prevention. Pharmacol Res. 2009;59(6):365-78. doi: 10.1016/j.phrs.2009.01.017. [PubMed 19429468].

14. Dhorajiya B, Malani M, Dholakiya B. Extraction and preservation protocol of anti-cancer agents from marine world. Chem Sci J. 2012;3:1.

15. Mousavi SH, Tayarani-Najaran Z, Hersey P. Apoptosis: from signalling pathways to therapeutic tools. Iran J Basic Med Sci. 2008;11(3):121-42.

16. Senthilkumar K, Kim SK. Marine invertebrate natural products for anti-inflammatory and chronic diseases. Evid Based Complement Alternat Med. 2013;2013:572859. doi: 10.1155/2013/572859. [PubMed: 24489586].

17. Mamelona J, Pelletier E, Girard-Lalancette K, Legault J, Karboune S, Kermasha S. Quantification of phenolic contents and antioxidant capacity of Atlantic sea cucumber, Cucumaria frondosa. Food Chem. 2007;104(3):1040-7.

18. Ogushi M, Yoshie-STARK Y, Suzuki T. Cytostatic activity of hot water extracts from the sea cucumber in Caco-2. Food Sci Technol Res. 2005;11(2):202-6.

19. Althunibat OY, Hashim RB, Taher M, Daud JM, Ikeda MA, Zali BI. In vitro antioxidant and antiproliferative activities of three Malaysian sea cucumber species. EurJ Sci Res. 2009;37(3):376-87.

20. Althunibat OY, Ridzwan BH, Taher M, Daud JM, Jauhari Arief Ichwan S, Qaralleh H. Antioxidant and cytotoxic properties of two sea cucumbers, Holothuria edulis lesson and Stichopus horrens Selenka. Acta Biol Hung. 2013;64(1):10-20. doi: 10.1556/ABiol.64.2013.1.2. [PubMed: 23567827].

21. Petrelli F, De Stefani A, Raspagliesi F, Lorusso D, Barni S. Radiotherapy with concurrent cisplatin-based doublet or weekly cisplatin for cervical cancer: a systematic review and meta-analysis. Gynecol Oncol. 2014;134(1):166-71. doi: 10.1016/j.ygyno.2014.04.049. [PubMed: 24793000].

22. Kaneyasu Y, Nagai N, Nagata Y, Hashimoto Y, Yuki S, Murakami Y, et al. Intra-arterial infusion chemotherapy using cisplatin with radiotherapy for Stage III squamous cell carcinoma of the cervix. Int J Radiat Oncol Biol Phys. 2009;75(2):369-77. doi: 10.1016/j.ijrobp.2009.02.081. [PubMed: 19735865].

23. Schmid MP, Franckena M, Kirchheiner K, Sturdza A, Georg P, Dorr $W$, et al. Distant metastasis in patients with cervical cancer after primary radiotherapy with or without chemotherapy and image guided adaptive brachytherapy. Gynecol Oncol. 2014;133(2):256-62. doi:10.1016/j.ygyno.2014.02.004. [PubMed: 24517875]. 